Research Article

\title{
Experimental Study on the Concrete with Compound Admixture of Iron Tailings and Slag Powder under Low Cement Clinker System
}

\author{
Ruidong Wu (i) and Juanhong Liu (D) \\ College of Civil and Resource Engineering, University of Science and Technology Beijing, Beijing 100083, China \\ Correspondence should be addressed to Juanhong Liu; liujuanhong66@126.com
}

Received 11 June 2018; Revised 30 July 2018; Accepted 3 September 2018; Published 23 September 2018

Academic Editor: Ali Nazari

Copyright (C) 2018 Ruidong Wu and Juanhong Liu. This is an open access article distributed under the Creative Commons Attribution License, which permits unrestricted use, distribution, and reproduction in any medium, provided the original work is properly cited.

\begin{abstract}
In order to study the performance of concrete with compound admixture of iron tailings and slag powder under low cement clinker system, the mixture ratio of different iron tailings powder and slag powder was designed to prepare C30 and C50 concrete. The workability, strength, carbonation depth, chloride diffusion coefficient, scanning electron microscopy (SEM), energy dispersive spectroscopy (EDS), and X-ray diffraction (XRD) of concrete were measured, respectively. The test results show that iron tailings powder is beneficial to improve the workability, and the strength of concrete decreases with the increase of iron tailings powder content, while the carbonation depth and chloride diffusion coefficient increase with the increase of iron tailings powder content. Under low cement clinker system, the iron tailings powder should not be used alone (below 70\% of mineral admixture). When the ratio of iron tailings to slag powder is $1: 1$, the strength, carbonation depth, chloride ion permeation coefficient, and the microstructure of concrete are roughly the same to that of concrete with single slag powder. So, the iron tailings powder can replace S95 grade slag powder in the same quantity. Iron tailings powder does not take part in hydration reaction, but it can improve particle gradation, reach close accumulation, and increase the quantity of central grains.
\end{abstract}

\section{Introduction}

Iron tailings are the waste slag of iron ore after ore dressing process. They are the residues of iron ore through crushing, screening, grinding, grading, gravity separation, flotation, or cyanidation, but there are still many parts of them which can be recycled [1]. Unfortunately, limited by the mineral processing technology, production equipment, and other scientific and technological factors, the current situation of iron tailings' secondary utilization in China is not optimistic. The data show that the comprehensive utilization ratio of tailings in China is only 7\%, which is far from $60 \%$ of developed countries such as the United States, Japan, and Russia, to name a few [2-7]. With the economic development, the infrastructure construction throughout the country is also ongoing, resulting in the increase of cement and concrete consumption. According to statistics, the national cement production in 2016 has exceeded 2.4 billion tons, which is more than half of the world's total cement production. At the same time, it must be noted that limestone, as a raw material, will produce a large amount of greenhouse gas in the high temperature calcination process.

It is understood that one ton of cement clinker could produce one ton of carbon dioxide. In China, the cement industry produces more than $5 \%$ of the world's total carbon emissions. Reducing cement consumption is an effective and necessary way to alleviate global warming and other environmental problems. Furthermore, high quantities of cement in the concrete can easily cause cracks. Cracks have great effect on the durability of concrete, resulting in poor corrosion resistance and short service life [8-10]. More and more scholars have found that using mineral admixtures instead of cement clinker can improve the shrinkage and microstructure of concrete and enhance the performance of concrete [11-14]. Therefore, reducing the amount of cement is of great significance to improve the durability of concrete, protect global 
environment, and save cost. Based on the above analysis, our study was conducted under the low cement clinker system.

With the rapid development of high performance concrete, the consumption of mineral admixtures, especially fly ash and slag powder, is increasing. These mixtures are commonly used but not abundant in some areas, which leads to the rising price of raw materials and market unbalance. Take economic and environmental factors into consideration, iron tailings powder is an excellent admixture for concrete. It can not only solve the problem of tailings utilization but also alleviate the shortage of concrete admixture. At present, some scholars have realized the significance of iron tailings as concrete admixture and focused their efforts on the strength and durability of concrete [15-19]. This paper aimed to explore the effect of iron ore tailings powder and slag powder composite admixture on the strength, durability, and micromorphology of concrete under low cement clinker system. The optimal dosage and mechanism of iron tailings powder were revealed finally.

\section{Materials and Mix Proportion}

2.1. Raw Materials. In order to eliminate the influence of some uncertain components in cement, a reference cement is adopted in the tests. Its main properties are shown in Table 1.

The water requirement ratio of iron tailings powder is $90 \%$, and the specific surface area is $450 \mathrm{~m}^{2} / \mathrm{kg}$. Iron tailings powder contains some metal elements, such as copper, iron, zinc, etc. The main chemical compositions are shown in Table 2.

Here, the S95 slag powder is used, with the density of $2.8 \mathrm{~g} / \mathrm{cm}^{3}$, the specific surface area of $485 \mathrm{~m}^{2} / \mathrm{kg}$, and the water requirement ratio of $96.2 \%$. All the indexes are in accordance with the national standard.

The coarse aggregate is divided into big stone and small stone, and the diameters are $10-20 \mathrm{~mm}$ for big stone and 5$10 \mathrm{~mm}$ for small stone The ratio of big stone to small stone is 8 : 2. The fine aggregate is made of natural river sand, with less mud (laboratory empirical value is $5.2 \%$ ). The fineness modulus is 2.7 , and the gradation is good. The additive is $20 \%$ polycarboxylic acid plasticizer (PC) produced by Sika Company.

2.2. Mix Proportion. Concerning environmental and economic factors, the proportion of cement to cementitious material in the mix ratio of C30 and C50 concrete of low cement clinker system is $40 \%$ and $50 \%$, respectively.

In order to study the effect of iron tailings powder on concrete performance, the ratio of iron tailings powder to slag powder was designed as $0: 10,3: 7,5: 5,5: 5$, and $10: 0$. Due to the low activity of iron tailings powder, with the increase of content, the water to binder ratio of concrete decreases with iron tailings powder, so the strength can meet the requirements. The water to binder ratio (W/B) decreases with the increase of iron tailings. Details are shown in Table 3.

\section{Results and Discussions}

After 10 groups of slump, carbonation depth, and chloride diffusion coefficient tests, experiment results are shown in Table 4.
3.1. Workability of Concrete. On the premise of using the same PC amount, the slump of concrete in each group is tested separately, as shown in Figure 1.

The slump of C30 and C50 concrete increases with the addition of iron tailings powder. When adding equal amount of admixture, the working performance of concrete with iron tailings powder is better than that of concrete with single slag powder. The addition of iron tailings fines will improve the particle size distribution of cementitious materials. However, there is a certain range of optimum particle gradation. The slump of C50 concrete with single iron tailings has a downward trend. Iron tailings powder is beneficial to improve the workability and pumping performance of concrete.

3.2. Compressive Strength of Concrete. Table 5 shows the testing of $3 \mathrm{~d}, 7 \mathrm{~d}$, and $28 \mathrm{~d}$ compressive strength of C30 and C50 concrete, respectively.

It can be seen from Table 5 that the strength of concrete decreases with the increase of iron tailings powder content. The $28 \mathrm{~d}$ compressive strength of groups A1 and B1 is the highest, and the strength of groups A5 and B5 is the lowest. $\mathrm{C} 30$ concrete has higher $\mathrm{W} / \mathrm{B}$ and less cementitious material. Because of the high activity of slag powder, the addition of iron tailings powder has an effect on the early strength of concrete. C50 concrete has lower W/B, larger amount of cementitious material, and longer hydration time of cementitious materials. Microaggregate effect of iron tailings powder plays a role and has little effect on early strength or even a slight improvement. From the perspective of strength, under the low clinker system, the iron tailings powder should not be mixed alone, and the iron tailings powder should not exceed $70 \%$ of the mineral admixture. The most reasonable ratio of iron tailings powder and slag powder for comprehensive economic and environmental consideration is $5: 5$.

3.3. Carbonation Depth. The carbonation depth of C30 and C50 concrete is measured, respectively, and the results are shown in Figure 2.

From Figure 2 and Table 5, it can be seen that the carbonation depth increases with iron tailings powder in the same strength grade, and the carbonation depth of concrete decreases with the increase of $28 \mathrm{~d}$ strength. The carbonization depth of A1 and B1 groups with single slag powder is the smallest, and the difference between the groups with iron tailings less than $70 \%$ of the mineral admixture and the single slag powder is not significant. The carbonization depth of the A5 and B5 group with single iron tailings powder is the largest, which increases by $36.4 \%$ and $163 \%$ compared with the single slag powder group. It indicates that the influence of iron tailings powder addition on high strength concrete is greater than that of low strength concrete.

3.4. Chloride Diffusion Coefficient. In order to study the chloride ion permeability of concrete, the chloride diffusion 
TABLE 1: Main properties of reference cement.

\begin{tabular}{|c|c|c|c|c|c|c|c|c|c|}
\hline \multicolumn{2}{|c|}{$\begin{array}{c}\text { Compressive } \\
\text { strength } \\
(\mathrm{MPa})\end{array}$} & \multicolumn{2}{|c|}{$\begin{array}{c}\text { Flexural } \\
\text { strength } \\
(\mathrm{MPa})\end{array}$} & \multicolumn{2}{|c|}{$\begin{array}{l}\text { Setting time } \\
\quad(\min )\end{array}$} & \multirow[t]{2}{*}{$\begin{array}{l}\text { Specific surface } \\
\text { area }\left(\mathrm{m}^{2} \cdot \mathrm{kg}^{-1}\right)\end{array}$} & \multirow[t]{2}{*}{ Fineness $(\mathrm{mm})$} & \multirow[t]{2}{*}{$\begin{array}{c}\text { Standard consistency } \\
\text { water consumption }(\%)\end{array}$} & \multirow[t]{2}{*}{ Soundness } \\
\hline $3 \mathrm{~d}$ & $28 \mathrm{~d}$ & $3 \mathrm{~d}$ & $28 \mathrm{~d}$ & Initial & Final & & & & \\
\hline 28.3 & 53.2 & 5.5 & 10.3 & 155 & 215 & 347 & 0.5 & 27.2 & Qualified \\
\hline
\end{tabular}

TABLE 2: Main chemical composition of iron tailings powder.

\begin{tabular}{lccccccc}
\hline Chemical composition & $\mathrm{SiO}_{2}$ & $\mathrm{CaO}$ & $\mathrm{MgO}$ & $\mathrm{Al}_{2} \mathrm{O}_{3}$ & $\mathrm{Fe}_{2} \mathrm{O}_{3}$ & $\mathrm{CuO}$ & $\mathrm{ZnO}$ \\
\hline Mass fraction (\%) & 67.59 & 4.02 & 1.18 & 4.57 & 10.88 & 0.23 & 0.11 \\
\hline
\end{tabular}

TABle 3: Concrete mix proportion $\left(\mathrm{kg} \cdot \mathrm{m}^{-3}\right)$.

\begin{tabular}{cccccccccc}
\hline Grade & Group & Cement & Iron tailings powder & Slag powder & Sand & Stone & Water & W/B & PC (\%) \\
\hline \multirow{5}{*}{ C30 } & A1 & 151 & 0 & 226 & 840 & 1018 & 151 & 0.40 & 0.9 \\
& A2 & 151 & 68 & 158 & 840 & 1018 & 147 & 0.39 & 0.9 \\
& A3 & 151 & 113 & 113 & 840 & 1018 & 143 & 0.38 & 0.9 \\
& A4 & 151 & 158 & 68 & 840 & 1018 & 140 & 0.37 & 0.9 \\
& A5 & 151 & 226 & 0 & 840 & 1018 & 136 & 0.36 \\
& B1 & 239 & 0 & 239 & 725 & 1071 & 139 & 0.29 & 1.4 \\
& B2 & 239 & 119.5 & 167 & 725 & 1071 & 134 & 0.28 & 1.4 \\
& B3 & 239 & 167 & 72 & 725 & 1071 & 129 & 0.27 & 1.4 \\
& B4 & 239 & 239 & 0 & 725 & 1071 & 124 & 0.26 & 1.4 \\
& B5 & 239 & & & 1071 & 119 & 0.25 & 1.4 \\
\hline
\end{tabular}

TABLE 4: Experiment results of concrete.

\begin{tabular}{lccc}
\hline Group & $\begin{array}{c}\text { Slump } \\
(\mathrm{mm})\end{array}$ & $\begin{array}{c}\text { Carbonation } \\
\text { depth }(\mathrm{mm})\end{array}$ & $\begin{array}{c}\text { Chloride diffusion coefficient } \\
\left(10^{-14} \mathrm{~m}^{2} \cdot \mathrm{s}^{-1}\right)\end{array}$ \\
\hline A1 & 200 & 2.2 & 129 \\
$\mathrm{~A} 2$ & 210 & 2.3 & 154 \\
$\mathrm{~A} 3$ & 210 & 2.5 & 177 \\
$\mathrm{~A} 4$ & 220 & 2.8 & 294 \\
$\mathrm{~A} 5$ & 220 & 3 & 377 \\
$\mathrm{~B} 1$ & 210 & 0.8 & 105 \\
$\mathrm{~B} 2$ & 220 & 1 & 98 \\
$\mathrm{~B} 3$ & 230 & 1.1 & 115 \\
$\mathrm{~B} 4$ & 240 & 1.5 & 211 \\
B5 & 230 & 2.1 & 241 \\
\hline
\end{tabular}

coefficient of concrete groups after 28 days of standard curing was measured by NEL method (see Figure 3).

With the increase of iron tailings powder content, the chloride diffusion coefficients of C30 and C50 concrete all show an overall increasing trend.

The chloride diffusion coefficient of $\mathrm{C} 30$ group was always higher than that of C50 group. When the content of iron tailings powder exceeds $70 \%$, the chloride diffusion coefficient increases significantly. Therefore, from the chloride ion penetration resistance perspective, iron tailings powder should not be mixed alone, and the amount of iron tailings powder should not exceed $70 \%$. Otherwise, there will be great influence on the chloride ion permeability of concrete.

When the content of the iron tailing powder is $50 \%$, the chloride diffusion coefficient of the concrete is little different from that of the single slag powder. The chloride diffusion coefficient of C30 group rises by $37.2 \%$, and the C50 group rises by $9.5 \%$. The gap is far less than the concrete with the iron tail mineral content of $70 \%$ and $100 \%$. In the case of no great influence antichloride permeability performance concrete, the addition of slag powder and iron tailings micropowder with the ratio of $5: 5$ is the most optimal determination.

3.5. Microscopic Test of Concrete. Laser particle size analysis of slag powder, iron tailings powder, and cementitious material system of 50\% slag powder and 50\% iron tailings powder is carried out. The results are shown in Figure 4.

Figure 4 shows that the particle size of slag powder is fine, the particle size of iron tailings powder is coarse, the particle size of $50 \%$ iron tailings powder and 50\% slag powder is between the two, the particle gradation is better, and the iron tailings powder plays a microaggregate effect. The effect of microaggregate can make all kinds of particles accumulate tightly. At the same time, after the introduction of iron tailings with very low activity, there are more unhydrated particles in the concrete. According to the central material hypothesis [20], such particles belong to the subcentral substance. The central network formed by the superposition of the favorable effect of subcentral quality is beneficial to the homogeneity of concrete. The addition of iron tailings powder can increase the number of central matter, reduce the distance between central matter, and 


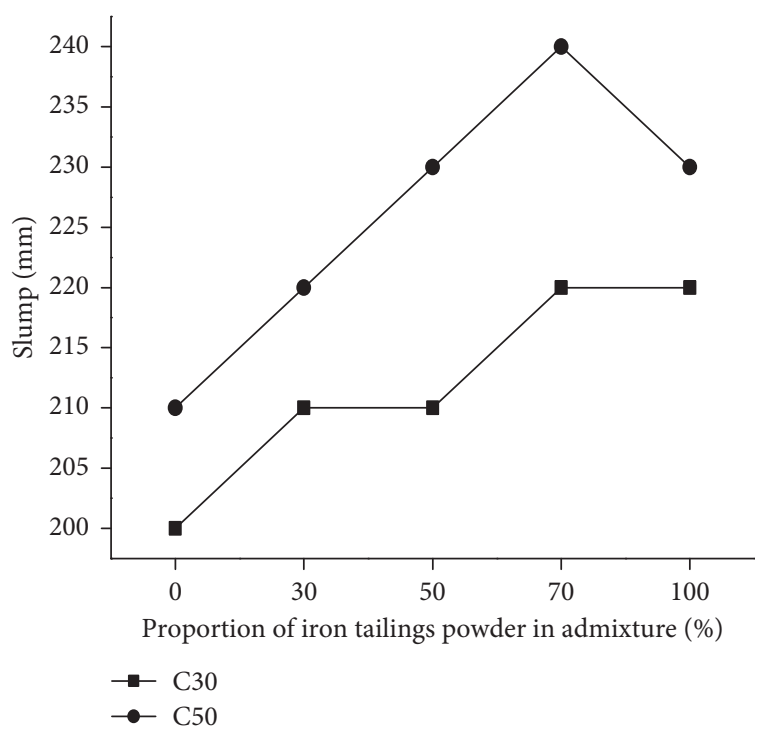

FIgURE 1: Slumps of concrete.

TABLE 5: Compressive strength at different ages of concrete (MPa).

\begin{tabular}{lccccccc}
\hline Group & $3 \mathrm{~d}$ & $7 \mathrm{~d}$ & $28 \mathrm{~d}$ & Group & $3 \mathrm{~d}$ & $7 \mathrm{~d}$ & $28 \mathrm{~d}$ \\
\hline A1 & 19.2 & 33.3 & 45.3 & B1 & 32.1 & 46.2 & 65.4 \\
A2 & 15.6 & 27.8 & 43.3 & B2 & 34.5 & 51.9 & 69.7 \\
A3 & 15.5 & 25.5 & 40.9 & B3 & 34.6 & 47.1 & 63.4 \\
A4 & 13.6 & 23.3 & 36.0 & B4 & 33.5 & 47.5 & 58.3 \\
A5 & 12.2 & 19.2 & 30.5 & B5 & 31.4 & 41.2 & 52.4 \\
\hline
\end{tabular}

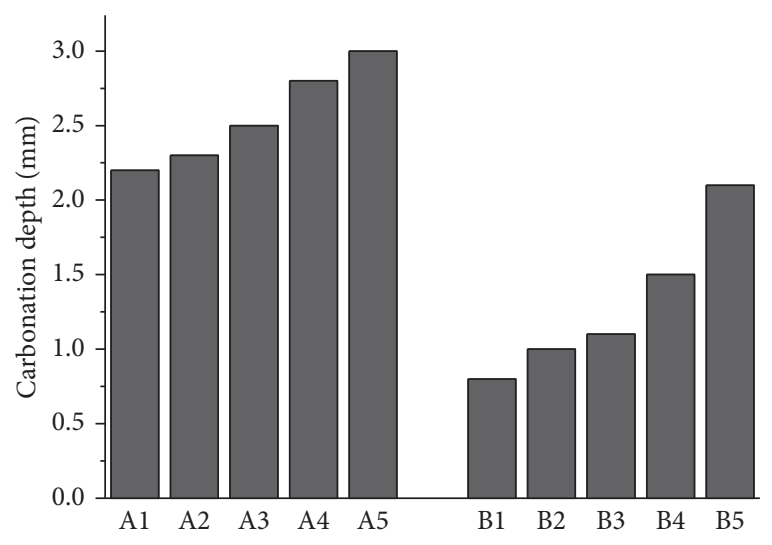

Figure 2: Concrete carbonation depth.

improve the effect degree, thus improving the performance of concrete eventually.

The $28 \mathrm{~d}$ microstructure of $\mathrm{A} 1, \mathrm{~A} 3, \mathrm{~A} 5, \mathrm{~B} 1, \mathrm{~B} 3$, and $\mathrm{B} 5$ concrete was observed by a scanning electron microscope (SEM), an energy dispersive spectrometer (EDS), and an $\mathrm{X}$-ray diffractometer (XRD), respectively, as shown in Figures 5-9.

The microstructure of C50 concrete is more dense than that of C30 concrete. The microcosmic morphology of A1 and $\mathrm{B} 1$ groups with single slag powder is the densest, and the hydration products are the most. The $\mathrm{A} 3$ and $\mathrm{B} 3$ groups are also dense. The hydration morphology is not very

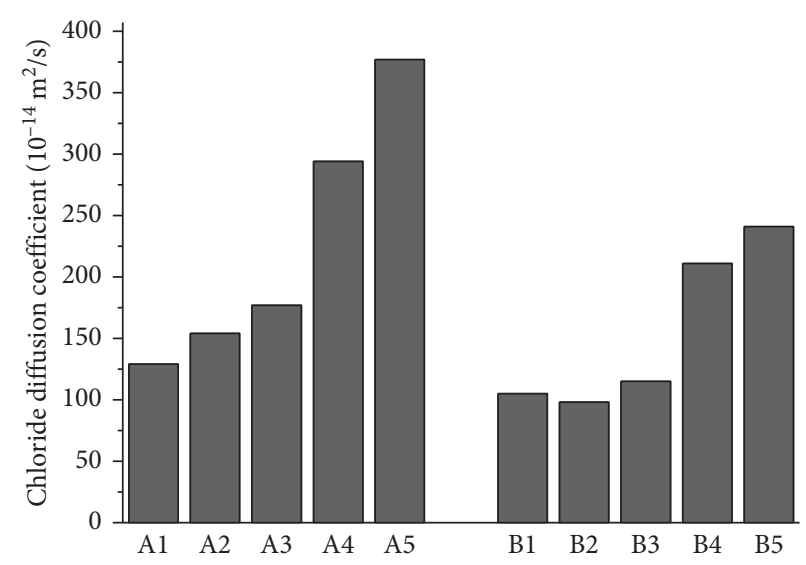

Figure 3: Chloride diffusion coefficient of concrete.

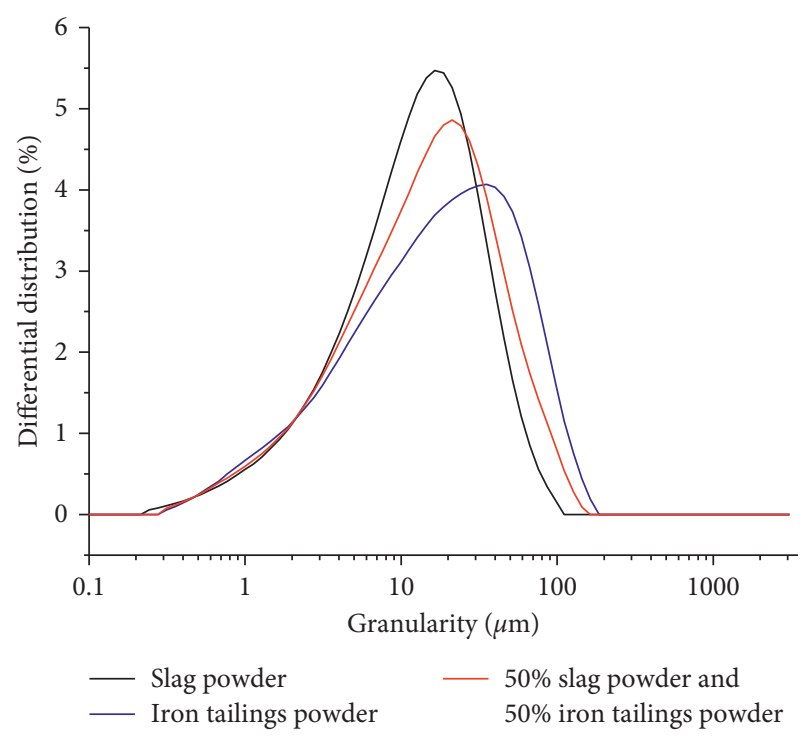

Figure 4: Particle size distribution of cementing materials.

different from that of $\mathrm{A} 1$ and $\mathrm{B} 1$. The microstructure of $\mathrm{A} 5$ and B5 groups is relatively loose. This is also consistent with the results of compressive strength, carbonation depth, and chloride permeability coefficient, which explains the macroscopic properties from microcosmic. The EDS spectrum shows that the main substance is $\mathrm{Si}$ and $\mathrm{O}$, which is the same as the main components of iron tailings. Combining with the SEM image and EDS energy spectrum, a small amount of iron tailings can be observed in the $\mathrm{A} 3$ and $\mathrm{B} 3$ groups, and a large amount of iron tailings are found in the A5 and B5 groups, indicating that iron tailings powder does not participate in hydration and is an inactive admixture. In the hydration process of cementitious materials, the main substances are calcium silicate hydrate $\left(3 \mathrm{CaO} \cdot 2 \mathrm{SiO}_{2} \cdot 3 \mathrm{H}_{2} \mathrm{O}, \mathrm{C}-\mathrm{S}-\mathrm{H}\right.$ gel), $\mathrm{SiO}_{2}, \mathrm{Ca}(\mathrm{OH})_{2}$, ettringite $\left(3 \mathrm{CaO} \cdot \mathrm{Al}_{2} \mathrm{O}_{3} \cdot 3 \mathrm{CaSO}_{4} \cdot 32 \mathrm{H}_{2} \mathrm{O}, \mathrm{AFt}\right)$, unhydrated cement particle tricalcium silicate $\left(3 \mathrm{CaO} \cdot \mathrm{SiO}_{2}, \mathrm{C}_{3} \mathrm{~A}\right.$ for short), and dicalcium silicate $\left(2 \mathrm{CaO} \cdot \mathrm{SiO}_{2}, \mathrm{C}_{2} \mathrm{~A}\right)$. The hydrated calcium silicate $\mathrm{C}-\mathrm{S}-\mathrm{H}$ gel is the most important hydration product, but the $\mathrm{C}-\mathrm{S}-\mathrm{H}$ belongs to the gel. And the XRD characterizes the crystal only, so there is no 


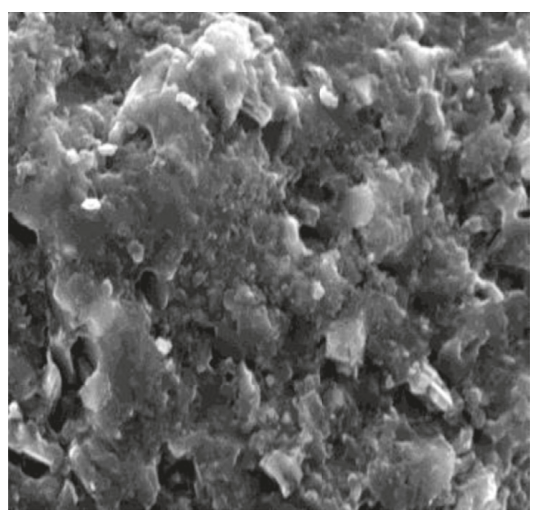

(a)

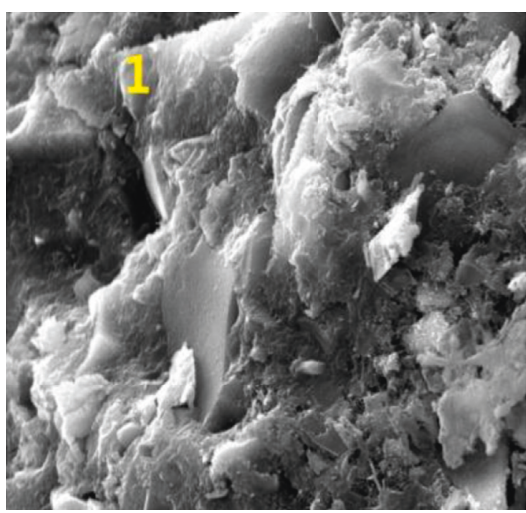

(b)

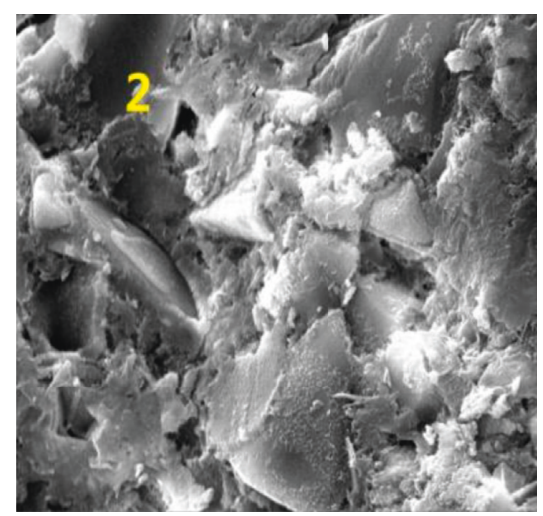

(c)

Figure 5: SEM images of C30 concrete: (a) A1, (b) A3, and (c) A5.

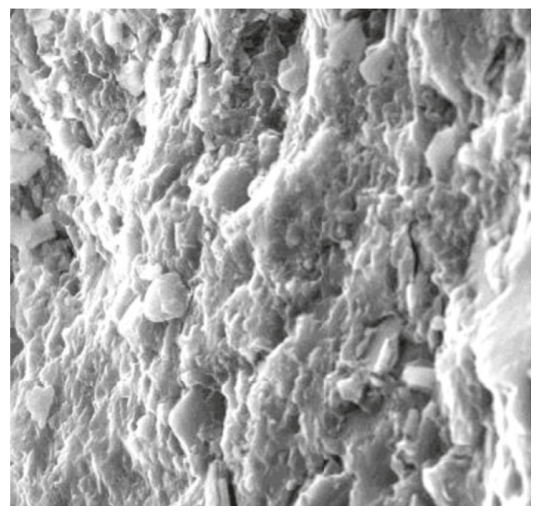

(a)

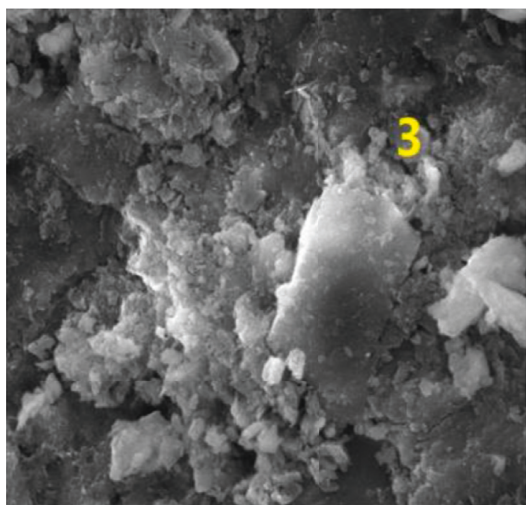

(b)

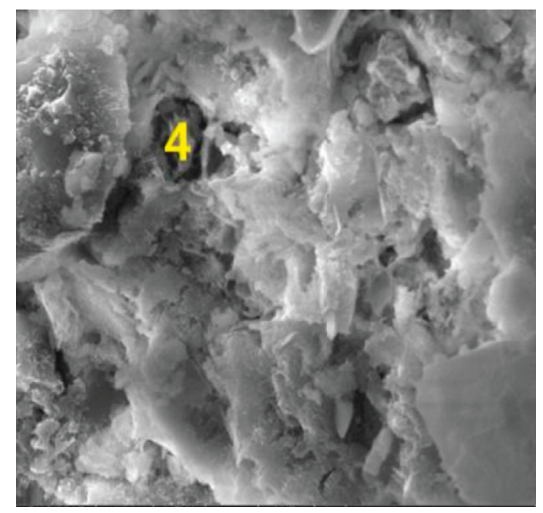

(c)

Figure 6: SEM images of C50 concrete: (a) B1, (b) B3, and (c) B5.

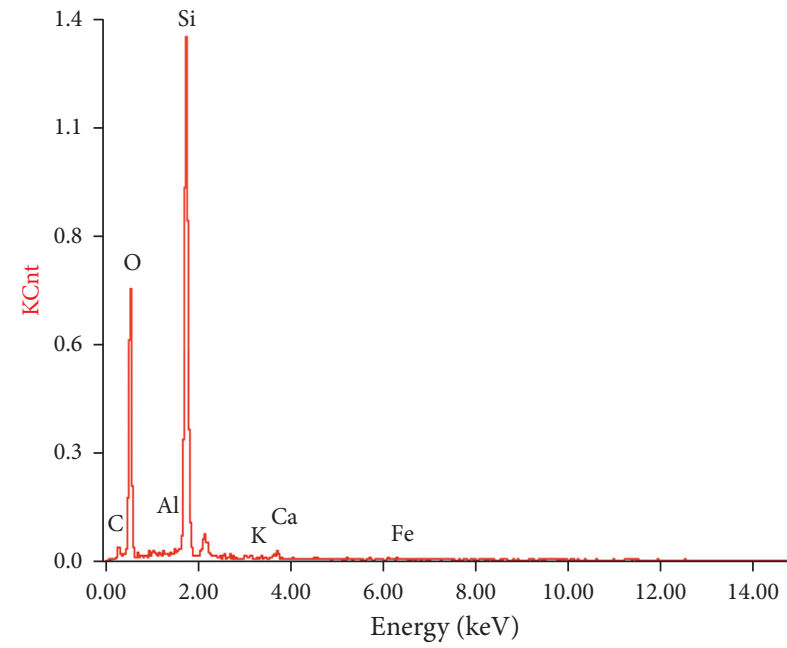

(a)

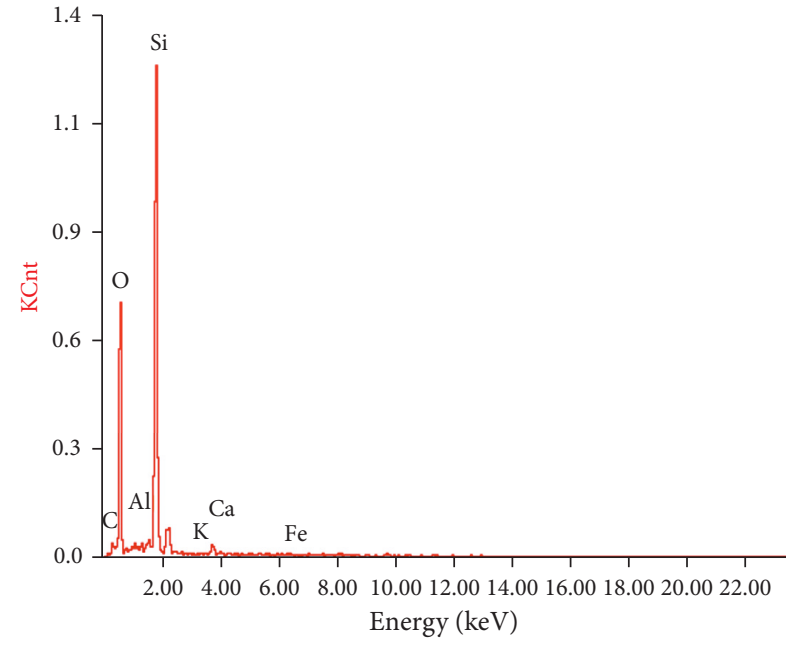

(b)

Figure 7: Energy spectrums of paste from Figures 5(b) “1” and 5(c) “2”: (a) EDS from Figure 5(b) and (b) EDS from Figure 5(c).

diffraction peak of the $\mathrm{C}-\mathrm{S}-\mathrm{H}$ gel in the XRD diagram. Figure 9 is the XRD Atlas of $\mathrm{C} 30$ and $\mathrm{C} 50$ concrete. $\mathrm{SiO}_{2}$ is mainly derived from cement, slag powder, and iron tailings. Through the XRD spectrum, the $\mathrm{SiO}_{2}$ diffraction peak of A5 and $\mathrm{B} 5$ groups with single iron tailings is far greater than $\mathrm{A} 1, \mathrm{~A} 3, \mathrm{~B} 1$, and $\mathrm{B} 3$ groups. The $\mathrm{SiO}_{2}$ 


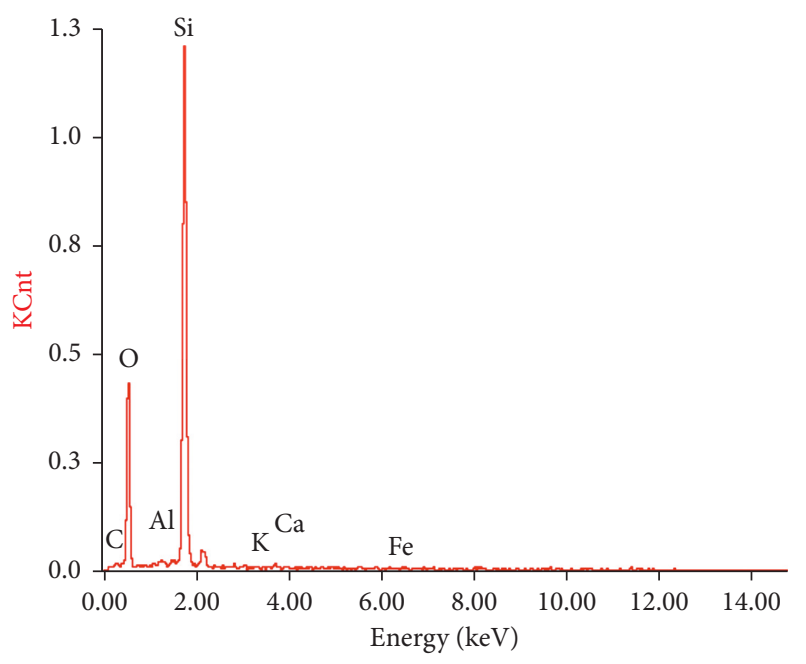

(a)

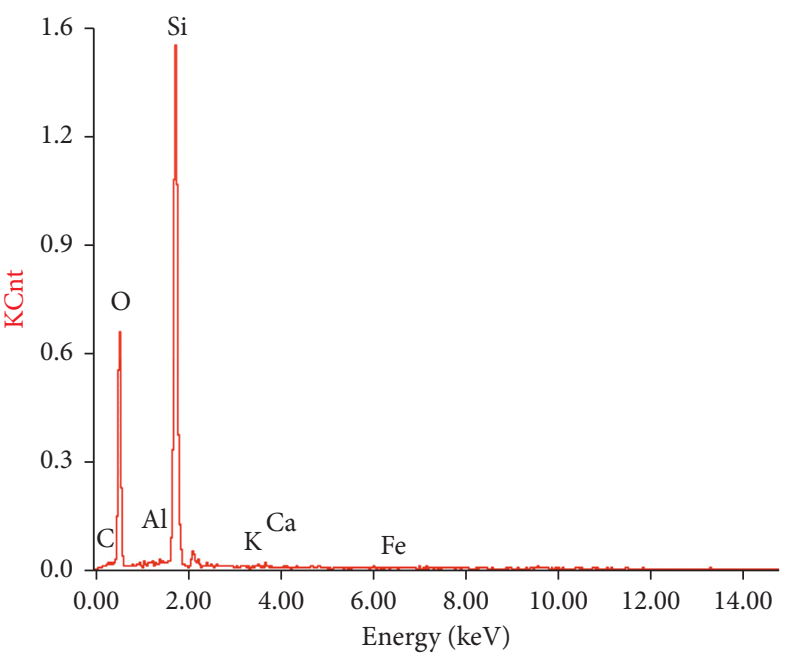

(b)

FIGURE 8: Energy spectrums of paste from Figures 6(b) “3” and 6(c) “4”: (a) EDS from Figure 6(b) and (b) EDS from Figure 6(c).

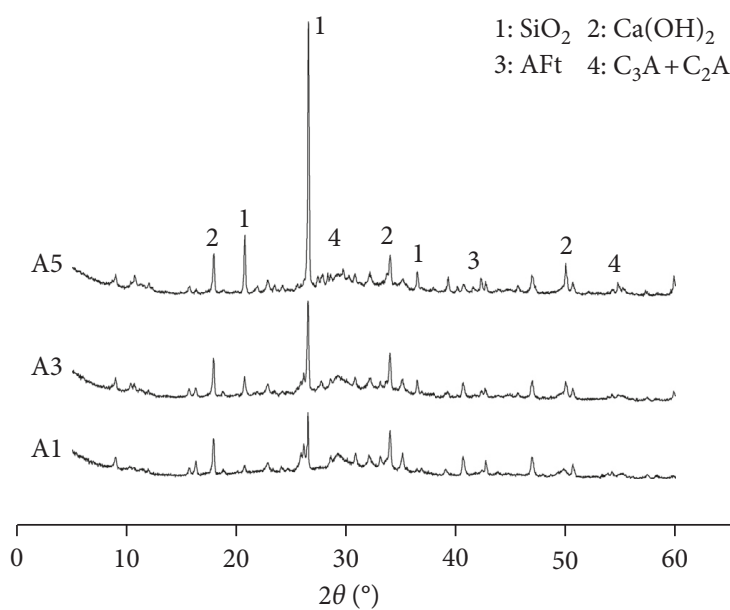

(a)

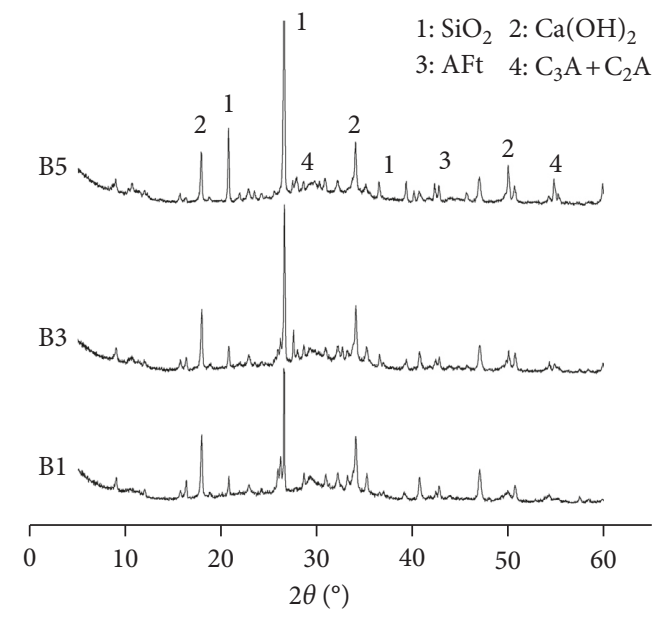

(b)

Figure 9: XRD of C30 and C50 concrete: (a) C30 and (b) C50.

diffraction peak of $\mathrm{A} 1$ and $\mathrm{B} 1$ group is the smallest because the activity of cement and slag powder is higher and most of the hydration reaction has occurred, while the iron tailings powder is not reacted, and the peak of the $\mathrm{SiO}_{2}$ diffraction peak is larger. It is also proved from microcosmic aspect that iron tailings powder basically does not participate in hydration reaction and has no activity.

Through microscopic test and analysis, it is found that iron tailings powder is inactive and should not be used alone. When the ratio of iron tailings powder to slag powder is $1: 1$, the microscopic morphology of concrete is similar to that of single mixed slag powder. The XRD spectra of hydration products are similar, thus explaining the performance of macroscopic performance. Iron tailings powder can replace the $S 95$ grade ore powder in the same quantity to achieve the purpose of solid waste utilization, energy saving, and emission reduction.

\section{Conclusions}

(1) Under low cement clinker system, iron tailings powder is beneficial to improve workability and pumping performance of concrete.

(2) The strength of $3 \mathrm{~d}, 7 \mathrm{~d}$, and $28 \mathrm{~d}$ of C30 and C50 concrete decreases with the increase of the iron tailings amount. For the depth of carbonization and the permeability coefficient of chloride ions, it is opposite.

(3) Under low cement clinker system, iron tailings powder should not be used alone, and the amount of iron tailings should not be greater than that of mineral admixture $70 \%$. When the ratio of iron tailings powder to slag powder is $1: 1$, the strength, carbonation depth, and chloride diffusion coefficient of concrete are not much different from that of single 
slag powder. Iron tailings powder can replace S95 grade slag powder in the same quantity.

(4) Iron tailings powder does not take part in hydration reaction, but it can improve particle gradation and accelerate close accumulation. When the ratio of iron tailings powder to slag powder is $1: 1$, the microstructure of concrete is similar to that of single slag powder.

\section{Data Availability}

The data used to support the findings of this study are available from the corresponding author upon request.

\section{Conflicts of Interest}

The authors declare that there are no conflicts of interest regarding the publication of this paper.

\section{Authors' Contributions}

Juanhong Liu and Ruidong Wu conceived and designed the experiments; Ruidong $\mathrm{Wu}$ performed the experiments; Juanhong Liu contributed materials; and Juanhong Liu and Ruidong $\mathrm{Wu}$ wrote the paper. All the authors read and approved the manuscript.

\section{Acknowledgments}

This research was financially supported by the National Natural Science Foundation of China (no. 11210107).

\section{References}

[1] Q. P. Yan, "Study on development and utilization of iron tailings in China," Iron and Steel Scrap of China, vol. 3, pp. 33-38, 2014.

[2] W. Zhao, C. L. Huo, M. Z. Liu, and H. M. Yang, "Research progress on the comprehensive utilization of non-ferrous metal mine tailings," China Resources Comprehensive Utilization, vol. 3, no. 29, pp. 24-28, 2011.

[3] Y. Zhang, J. F. Li, and C. H. Suo, "Comprehensive utilization of mine tailings and its environmental control significance," Agriculture and Technology, vol. 20, no. 4, pp. 56-57, 2000.

[4] Y. Sun, H. Wang, L. Liu, and X. Wang, "Solid wastes utilization in the iron and steel industry in China: towards sustainability," Mineral Processing and Extractive Metallurgy, vol. 126, no. 1-2, pp. 41-46, 2017.

[5] S. H. Zhang, X. X. Xue, R. Liu, and Z. F. Jin, "Current situation and prospect of the comprehensive utilization of mining tailings," Mining and Metallurgical Engineering, vol. 25, no. 3, pp. 44-47, 2005.

[6] S. H. Zhang, X. X. Xue, and Z. F. Jin, "Current situation and comprehensive utilization of iron ore tailings resources in our country," Journal of Materials and Metallurgy, vol. 3, no. 4, pp. 241-245, 2004.

[7] M. Guo, Y. S. Lu, Z. H. Jia, and Z. J. Zhong, "The methods of mining tailings and waste rock resourcing," China Mining Magazine, vol. 4, pp. 35-37, 2009.

[8] R. W. Burrows, The Visible and Invisible Cracking of Concrete, American Concrete Institute, Michigan, United States, 2012.
[9] H. Z. Lian and S. F. Han, "What kind of cement is needed for modern concrete," Cement, vol. 9, pp. 13-18, 2006.

[10] J. H. Liu and S. M. Song, "Discussion on the merits and demerits of cement and its future," Concrete World, vol. 5, pp. 58-63, 2015.

[11] B. Chen, Y. M. Zhang, and L. P. Guo, "Investigation of drying shrinkage of high volume fly ash concrete," Journal of Southeast University, vol. 37, no. 2, pp. 334-338, 2007.

[12] J. Z. Liu, W. Sun, C. W. Miao, and J.P. Liu, "Effect of mineral admixtures on drying and autogenous shrinkage of concrete with low water-to-binder ratio," Journal of Southeast University, vol. 39, no. 3, pp. 580-585, 2009.

[13] H. Li, W. Sun, and X. B. Zuo, "Effect of mineral admixtures on sulfate attack resistance of cement-based materials," Journal of the Chinese Ceramic Society, vol. 40, no. 8, pp. 1119-1126, 2012.

[14] N. Džigita, G. Giedrius, and S. Gintautas, "Properties of concrete modified with mineral additives," Construction and Building Materials, vol. 135, pp. 37-42, 2017.

[15] X. Y. Ma, A. L. Wang, and X. Yang, "Study on the influence of iron tailings powder compound admixture on concrete performance," China Concrete, vol. 7, pp. 90-95, 2013.

[16] B. G. Oladeji and S. C. Aduloju, "Investigation of compressive strength of concrete from cement and iron-ore tailings mixture," Scholars Journal of Engineering and Technology, vol. 3, pp. 560-562, 2015.

[17] A. L. Wang, X. Y. Ma, and X. Yang, "Study on activity of iron tailings powder as concrete admixture," China Concrete, vol. 8, pp. 66-69, 2013.

[18] X. Y. Zhang, Q. Song, H. Li, and X. D. Fan, "Effect of iron tailings powder on properties of $\mathrm{C} 40$ concrete," Bulletin of the Chinese Ceramic Society, vol. 32, no. 12, pp. 2559-2563, 2013.

[19] Y. F. Hou and S. R. Zhao, "Effect of iron tailings powder on concrete properties," Fly Ash Comprehensive Utilization, vol. 3, pp. 17-24, 2015.

[20] Z. W. Wu, "High performance concrete--Green concrete," China Concrete and Cement Products, vol. 1, pp. 3-6, 2000. 


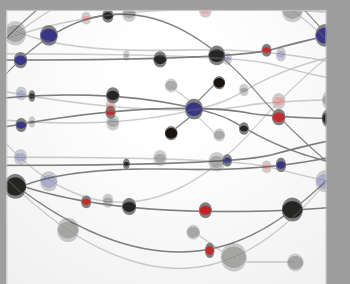

The Scientific World Journal
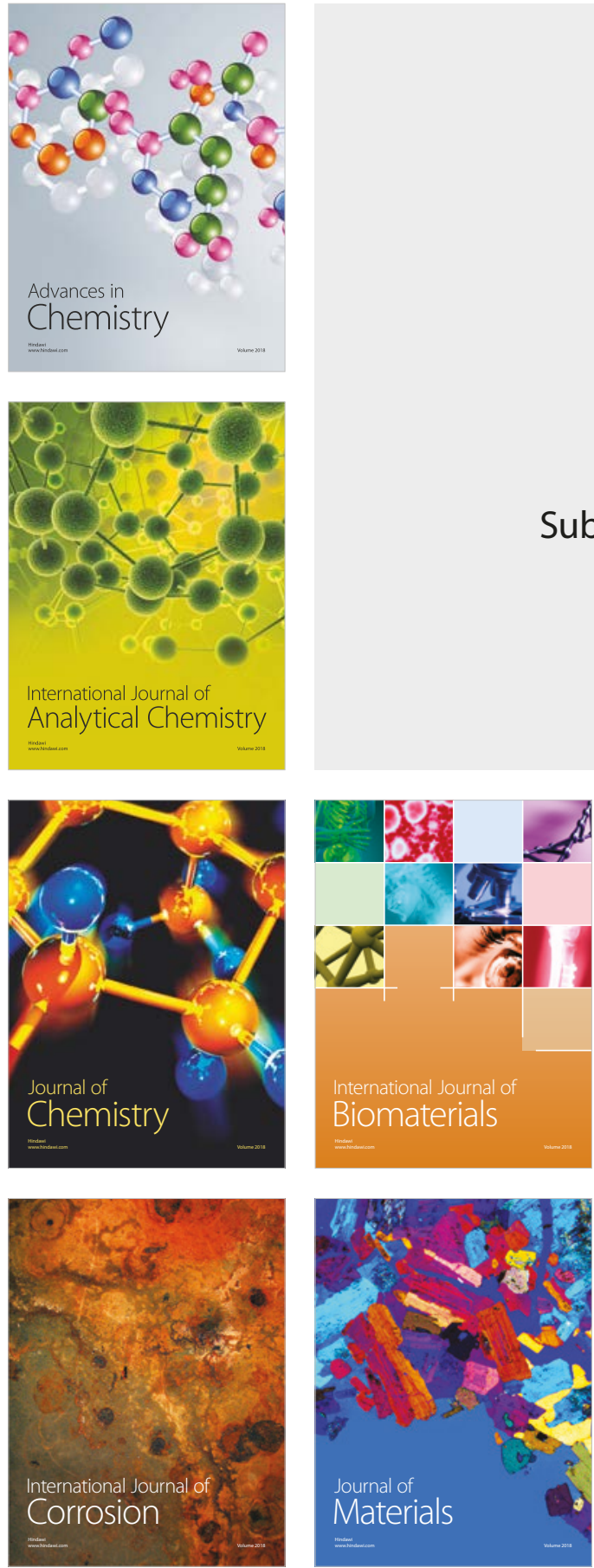

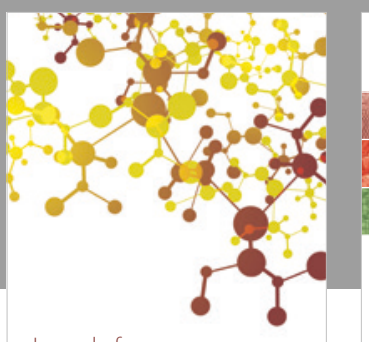

Journal of

Applied Chemistry
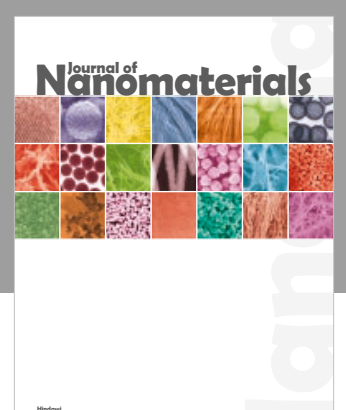

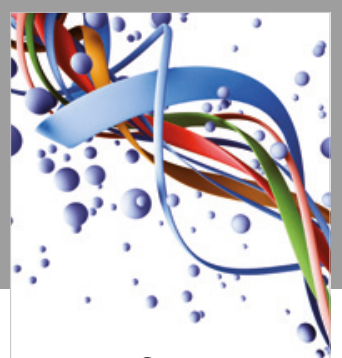

Scientifica

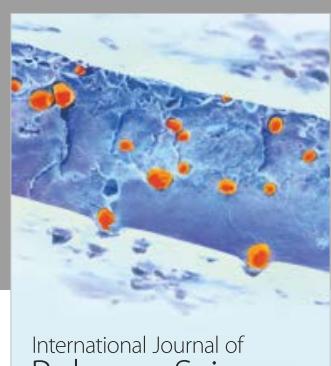

Polymer Science

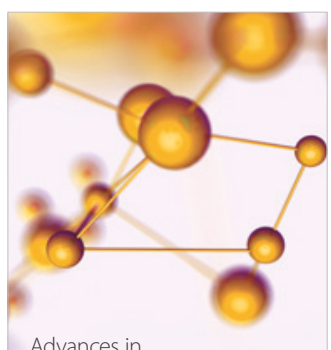

Physical Chemistry
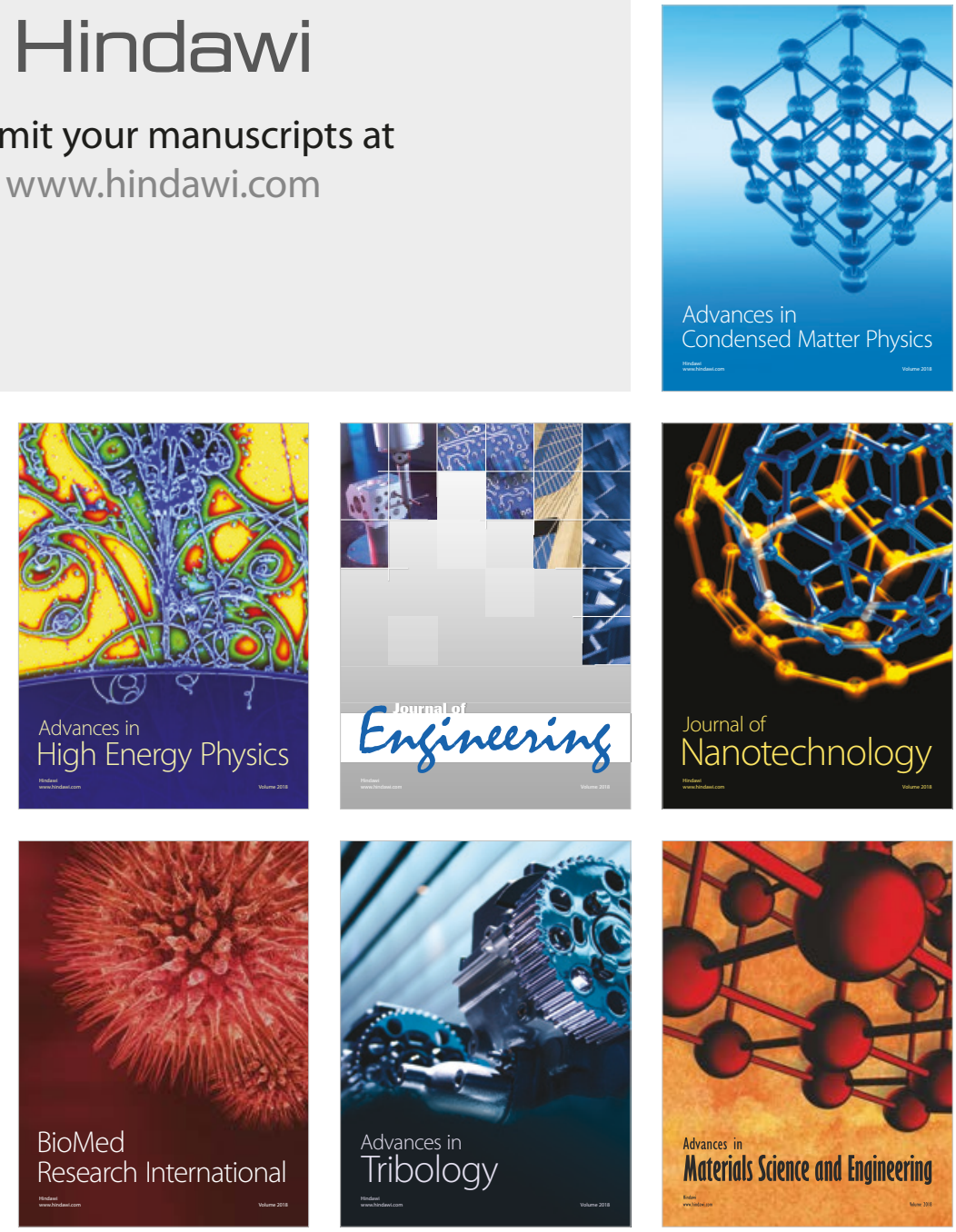